\title{
Computational Studies of Formation Silicon Nanotubes-Propylthiouracil Hybrids to Investigate its Role in Confining Propylthiouracil Drug
}

\author{
A. SHAMELI ${ }^{1 *}$, E. BALALI ${ }^{2}$, R. KHADIVI ${ }^{2}$ and S. SHOJAEI ${ }^{2}$ \\ 'Department of Chemistry, Omidiyeh Branch ,Islamic Azad University , Omidiyeh ,Iran. \\ ${ }^{2}$ Department of Chemistry, Pharmaceutical Sciences Branch, Islamic Azad University, Tehran, Iran. \\ ${ }^{*}$ Corresponding author E-mail: shameli678@gmail.com \\ http://dx.doi.org/10.13005/ojc/320132
}

Received: January 25, 2016; Accepted: March 04, 2016

\begin{abstract}
In order to search for the interaction between Propythiouracil(ptu) and infinitely long armchair single-walled silicon nanotubes (SiNTs) is investigated using density functional theory (DFT). The structures of individual counterparts and hybrids have been optimized and the molecular properties have been evaluated. The Nuclear magnetic resonance spectroscopy (NMR) are witness to the substantial changes in the electronic properties of the SiNTs systems following the attachment of the ptu with the tube surface.
\end{abstract}

Key words: Silicon Nanotubes, Propythiouracil, Density Functional Theory, NMR.

\section{INTRODUCTION}

The Propylthiouracil was synthesized by George W. Anderson and et al ${ }^{1}$, with propylthiouracil (ptu) is among the most commonly employed antithyroidal drugs in use, for the treatment of hyperthyroidism ${ }^{2}$. the FDA published an alert "notifying healthcare professionals of the risk of serious liver injury, including liver failure and death, with the use of $\mathrm{ptu}^{3}$. As a result, ptu is no longer recommended in non-pregnant adults and in children as the front line antithyroid medication ${ }^{4}$. In this study, we performed first-principles simulation to study the interaction between Silicon Nanotubes and ptu.
Carbon nanotube research has been an extremely active field since their discovery by lijima and structural identification ${ }^{5,6}$. They possess fascinating electronic, structural, and mechanical properties, and they could be used in a wide range of electromechanical devices as well as in the fabrication of robust and/or highly conducting composites ${ }^{7,8}$. Due to their unique and diverse physical properties, quasi-onedimensional Nanotubes show great promise to serve as active components in various nanoscale devices including sensitive chemical and biological detectors, electronic properties have been demonstrated to be effective gas chemical sensors for detecting many 
molecules, such as $\mathrm{NH}_{3},{ }^{9} \mathrm{O}_{2},{ }^{10} \mathrm{NO}_{2},{ }^{11}$ and etc. In recent years, CNTs, BNNTs, AINNTs, SiNTs have been proposed to detect different molecules using density functional theory (DFT) calculation ${ }^{12}$.

\section{Computational details}

The SiNTs models considered here are $(5,5)$ armchair with their ends hydrogen atoms. The $(5,5)$ model consists of $100 \mathrm{Si}$ and $20 \mathrm{H}$ atoms. Interaction of Propylthiouracil molecule with the SiNTs systems has been studied in the gas. This reduces the computational cost in comparison to treating each molecule separately. All the structures were optimized at $6-31+G^{*} / B 3 L Y P$ level of theory ${ }^{13}$.

\section{RESULT AND DISCUSSION}

The adsorption energy of the adsorb ate ptu with the SiNTs is calculated according to the formula:

$$
\Delta \mathrm{E}_{\mathrm{ads}}=\mathrm{E}_{\mathrm{ptu}-\mathrm{SiNTs}}-\left(\mathrm{E}_{\mathrm{SiNTs}}+\mathrm{E}_{\mathrm{ptu}}\right)
$$

The molecular systems include the individual SiNTs, the individual ptu and hybrid SiNTsptu (Fig. 1).

Fig. 1. Individual SiNTs and ptu model. The connecting atomic sites are $\mathrm{Si} 7$ and $\mathrm{N} 1$ atoms in the SiNTs-ptu hybrids.

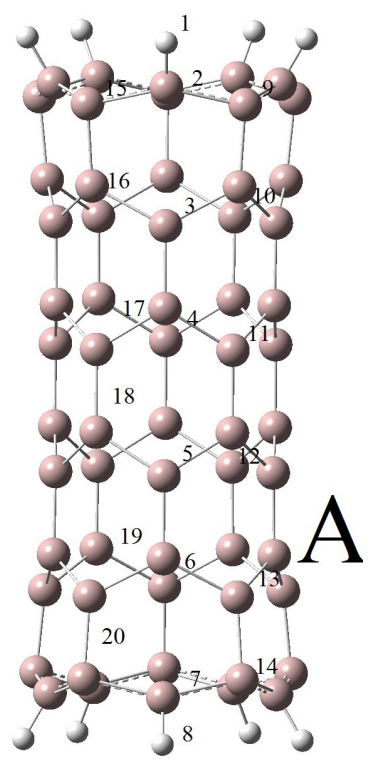

Vibration frequencies have been also calculated at the same level to confirm that all the stationary points correspond to true minima on the potential energy surface.

The molecular systems include the individual SiNTs, the individual Ptu and hybrid SiNTs -Ptu (Fig. 1).

This work is to investigate the influence of SiNTs, as a representative nanostructure, on the optimized structures and properties of Ptu. To this aim, molecular and atomic properties (Tables 1 ) have been computationally evaluated for the investigated systems.

The resulting approaches for chemical shielding (CS) calculations in the principal axis system (PAS) with the order of $\sigma_{33}>\sigma_{22}>\sigma_{11}{ }^{13}$ are converted into measurable NMR parameters (the chemical shielding isotropic CS (CS') and the chemical shielding anisotropic $C S\left(C S^{A}\right)$ parameters) using $\mathrm{Eq}_{\mathrm{s}}$. (2) and (3) ${ }^{14}$ and the NMR parameters of ${ }^{29} \mathrm{Si}$ and ${ }^{13} \mathrm{C}$ atoms for the investigated models of the SiNTs and SiNTs-Ptu are summarized in Table 2.

$$
\begin{aligned}
& \operatorname{CS}^{\prime}=1 / 3\left(\sigma_{11}+\sigma_{22}+\sigma_{33}\right) \\
& \operatorname{CS}^{A}=\sigma_{33}-1 / 2\left(\sigma_{22}+\sigma_{11}\right)
\end{aligned}
$$

Fig. 1: The optimized structure of SNTs and Ptu model a) SNTs b) Ptu, c) SNTs-Ptu complex 
Table 1: properties atomic and physical SiNTs(modelA), Ptu-SiNTs, Ptu

\begin{tabular}{|c|c|c|c|c|c|}
\hline \multirow{2}{*}{\multicolumn{2}{|c|}{$\begin{array}{c}\text { Model } A \\
\text { bond lengths }\left(A^{0}\right) 6-31+G^{*}\end{array}$}} & \multicolumn{2}{|l|}{ Model B } & \multicolumn{2}{|l|}{ Model C } \\
\hline & & bond lengths $\left(A^{0}\right)$ & $6-31+G^{*}$ & bond lengths $\left(A^{0}\right)$ & $6-31+G^{*}$ \\
\hline $\mathrm{Si}-\mathrm{H} 1-2$ & 1.43 & $\mathrm{Si}-\mathrm{H} 1-2$ & 1.43 & $\mathrm{C}=\mathrm{O} 23-28$ & 1.43 \\
\hline Si-Si 2-9 & 2.17 & Si-Si 2-9 & 2.21 & $C=S 21-27$ & 1.78 \\
\hline Si-Si 2-15 & 2.17 & $\mathrm{C}=\mathrm{O} 23-28$ & 1.43 & C-N 21-26 & 1.39 \\
\hline Si-Si 9-10 & 2.22 & $C=S$ 21-27 & 1.78 & C-N 21-22 & 1.39 \\
\hline Angel & & Angel & & Angel & \\
\hline Si-H-Si 1-2-9 & 104.58 & Si-H-Si 1-2-9 & 122.76 & S-C-N 27-21-22 & 120.01 \\
\hline Si-H-Si 1-2-15 & 104.58 & Si-H-Si 1-2-15 & 122.76 & 0-C-N 28-23-22 & 119.99 \\
\hline Si-Si-Si 2-9-10 & 118.54 & Si-Si-Si 2-9-10 & 119.71 & N-C-N 26-21-22 & 119.99 \\
\hline tip diameter(A0) & 17.54 & tip diameter(A0) & 17.54 & tip diameter(A0) & 8.11 \\
\hline DM(Debye) & 0.016 & DM(Debye) & 7.51 & DM(Debye) & 6.21 \\
\hline$E(k e v)-472.8$ & $\mathrm{E}(\mathrm{kev})$ & -496.11 & $\mathrm{E}(\mathrm{kev})$ & -23.28 & \\
\hline$\Delta$ Eads $(e V)$ & 0 & $\Delta$ Eads $(e V)$ & -30 & $\Delta$ Eads $(e V)$ & 0 \\
\hline
\end{tabular}

Table 2: NMR parameters SiNTs, SiNNTs-Ptu

\begin{tabular}{|c|c|c|c|c|}
\hline \multicolumn{2}{|c|}{ SiNNTs } & \multicolumn{2}{|c|}{ SiNNTs-Ptu } & \multirow[b]{2}{*}{$\mathrm{Si} 2$} \\
\hline CS & CA & CS & CA & \\
\hline 378.0077 & 145.2369 & 408.8515 & 87.9639 & Si4 \\
\hline 363.7112 & 181.1276 & 364.4184 & 118.0616 & si9 \\
\hline 198.3024 & 210.4733 & 188.2051 & 134.0988 & Si10 \\
\hline 358.9619 & 111.5763 & 364.9487 & 2.359 & Si14 \\
\hline 224.079 & 182.861 & - & - & Si15 \\
\hline 396.1703 & 198.2104 & 409.5577 & 123.0493 & \\
\hline
\end{tabular}

Three sets of optimization processes have been performed to generate the stabilize structures. The first set of optimizations has been performed for the free Ptu structures and the second set have has been performed for the free SiNTs. At the third set, the hybrid models including the SiNTs and Ptu together (Fig. 1) have been optimized to see the relaxation of each Ptu model on the surface of SiNTs.

\section{CONCLUSION}

In this paper, we performed the DFT calculations to study the interaction between
SiNTs and ptu molecules, it is found that ptu can be chemically adsorbed on SiNTs with appreciable adsorption energies. The ptu molecule uses its $\mathrm{O}, \mathrm{S}$, $\mathrm{H}$ and $\mathrm{C}$ atoms to bond with $\mathrm{Si}$ atom, respectively, of the tube, forming a four-membered ring. Significant charges are transferred from SiNTs to ptu molecules, which lead to changes of conductance of SiNTs and render this kind of nanotubes suitable for ptu detection.

\section{ACKNOWLEDGMENT}

The authors are grateful to the Department of Chemistry, Omidiyeh Branch, Islamic Azad University, Omidiyeh, Iran for the financial support. 


\section{REFERENCES}

1 Anderson G. W., Halverstadt I. F., Wilbur Roblin H., Richard O. J. Am. Chem.S. 1945, 67 (12), 2197-2200.

2. Antoniadis C. D., Corban G., Hadjikakou S. K., Hadjiliadis N., Kubicki M., Warner S., Butler I.S. Eur. J. Inorg. Chem. 2003, 1635"1640.

3. "Propylthiouracil (PTU)-Induced Liver Failure". FDA. Retrieved 2009-05-03.

4. Bahn R.S., Burch H.S., Cooper D.S. Thyroid. 2009, 19 (7), 673-4

5. lijima S. Nature. 1991, 354, 56"58.

6. Oberlin A., Endo M., Koyama T. J. Cryst. Growth. 1976, 32, 335"349.

7. Endo M., Hayashi T., Kim Y. A., Terrones M., Dresselhaus M. S. Philos. Trans. R. Soc. London, Ser. A. 2004, 362, 2223"2238.

8. McNally T., Po/tschke P., Halley P., Murphy M., Martin D., Bell S. E. J., Brennan G. P., Bein D., Lemoine P., Quinn J. P. Polymer, 2005, 46, 8222"8232.

9. Kong J., Franklin N., Zhou C., Chapline M., Peng S., Cho K., Dai, H. Science 2000, 287, 622-625.

10. a) Collins P. G., Bradley K., Ishigami M., Zettl A. Science, 2000, 287, 1801-1804. b) Balali E., Shameli A., Naeimi H., Ghanbari M. M. Orient. J. Chem., 2013, 29(4), 1611-1614. C) Azizian J., Shameli A., Balalaie S., Ghanbari M. M., Zomorodbakhsh S., Entezari M., Bagheri S., Fakhrpour G. Orient. J. Chem., 2012, 28(1), 327-332 d) Balalaie S., Azizian
J., Shameli A., Bijanzadeh H.R. Synthetic Commun. 2013, 43, 1787-1795 e) Shameli Akandi A., Balali E., Mosavat T., Ghanbari M. M., Eazabadi A. Orient. J. Chem., 2014, 30(2), 587-591. F) Azizian, J., Shameli A., Balalaie S., Zomorodbakhsh S. Orient. J. Chem., 2012, 28(1), 221-227.

11. Li J., Lu Y. J., Ye Q., Cinke M., Han J., Meyyappan M. Nano Lett. 2003, 3, 929-933.

12. Mirzaei M., Yousefi M. Superlattices Microstruct. 2013, 55, 1-7.

13. Frisch M. J., Trucks G. W., Schlegel H. B., Scuseria G. E., Robb M. A., Cheeseman J. R., Zakrzewski V. G., Montgomery J. A., Stratmann R. E., Burant J. C., Dapprich S., Millan J. M., Daniels A. D., Kudin K. N., Strain M. C., Farkas O., Tomasi J., Barone V., Cossi M., Cammi R., Mennucci B., Pomelli C., Adamo C., Clifford S., Ochterski J., Petersson G. A., Ayala P. Y., Cui Q., Morokuma K., Malick D. K., Rabuck A. D., Raghavachari K., Foresman J. B., Cioslowski J., Ortiz J. V., Baboul A. G., Stefanov B. B., Liu G., Liashenko A., Pikorz P., Komaromi I., Gomperts R., Martin R. L., Fox D. J., Keith T., Al-Laham M. A., Peng C.Y., Nanayakkara A., Gonzales C., Challacombe M., Gill P. M. W., Johnson B., Chen W., Wong M. W., Andreas J. L., Head-Gordon M., Reploge E. S., Pople J. A., GAUSSIAN 03, Gaussian, Inc., Pittsburgh, PA, 2003. 